\title{
Mortality from asthma: a new epidemic in New Zealand
}

\author{
RODNEY T JACKSON， ROBERT BEAGLEHOLE， HAROLD H REA， DAVID C SUTHERLAND
}

\begin{abstract}
Trends in mortality attributed to asthma in the 5-34-year age group were examined in New Zealand, Australia, England and Wales, the United States, Canada, and West Germany for the years 1959-79. An epidemic of deaths from asthma occurred in the mid-1960s in New Zealand, Australia, and England and Wales but not in the other countries. In Australia and England and Wales the death rate quickly returned to pre-epidemic levels, but in New Zealand the decline in mortality was slow, and by 1974 the death rate was still almost double the pre-epidemic level. Of great concern was an abrupt increase in reported deaths from asthma in New Zealand after 1976 with the mortality rate during $1977-9$ being greater than during the previous epidemic. In contrast, asthma mortality had remained relatively stable in the other populations.

The new epidemic in New Zealand was investigated and appeared to be real. It could not be explained by changes in the classification of deaths from asthma, inaccuracies in death certification, or changes in diagnostic fashions. The most likely explanation appeared to be related to the management of asthma in New Zealand, and this is being investigated.
\end{abstract}

\section{Introduction}

An epidemic of deaths from asthma in Britain, Australia, and New Zealand in the mid-1960s stimulated much interest in the treatment of asthma and in factors leading to death from asthma. The striking increase in asthma mortality in those countries

School of Medicine, University of Auckland, Auckland, New Zealand RODNEY T JACKSON, MB, CHB, Medical Research Council training fellow in epidemiology, department of community health

ROBERT BEAGLEHOLE, MD, FRACP, senior lecturer in epidemiology, department of community health

DAVID C SUTHERLAND, FRACP, senior lecturer in clinical immunology, department of medicine

Chest Medical Unit, Green Lane Hospital, Auckland

HAROLD H REA, MD, MRCP, physician after years of relative stability in mortality rates suggested that some new factor in the treatment of asthma may have been the cause. ${ }^{1}$ The epidemic began to subside in Britain and Australia in 1967 and appeared to do so in New Zealand one to two years later, but no completely satisfactory explanation was found. ${ }^{2-5}$

Recently an apparent increase in deaths from asthma in young people in Auckland has been described, and the additive toxicity of beta ${ }_{2}$-agonists and oral theophylline was suggested as a cause ${ }^{6}$ We have examined recent trends in asthma mortality in New Zealand and in five other populations, two of which had experienced the previous epidemic. We also looked more closely at deaths from asthma in Auckland in 1981. Our objectives were (a) to determine whether New Zealand was experiencing another epidemic of deaths attributed to asthma and $(b)$ if confirmed, to determine whether this was real or due to inaccuracies in death certification, changes in diagnostic fashions, changes in the classification of deaths, or changes in the population; and (c) to compare recent trends in asthma mortality in New Zealand with trends in other countries.

\section{Methods}

INTERNATIONAL TRENDS IN ASTHMA MORTALITY

Mortality rates for asthma during 1959-79 in the 5-34-year age group were derived from the national health statistics of New Zealand, Australia, England and Wales, the United States, Canada, and West Germany. ${ }^{4-13}$

INTERPRETATION OF TRENDS

\section{Classification changes}

Since there had been several revisions of the International Classification of Diseases (ICD) in the period under consideration, these changes were examined to determine their influence on asthma mortality. ${ }^{14}$

\section{Differences in diagnostic fashions}

As differences in diagnostic fashions may have caused shifts in the classification of deaths from asthma into other respiratory disease categories, deaths in these other categories in the 5-34-year age group 
during $1968-78$ were reviewed. ${ }^{7-13}$ All deaths due to respiratory diseases other than asthma have been summed because, except for deaths from pneumonia, the numbers were small.

\section{Death certificate validation}

All deaths certified as due to asthma in Auckland (population $820000 ; 426000$ aged 5-34 years) during 1981 in people aged 5-34 years were identified by a routine review of death certificates and coroners' necropsies. In each case standard questionnaires relating to medical history and the circumstances of death were given to the closest relative and the patient's general practitioner. Two respiratory physicians reviewed these questionnaires (and medical records when available) to determine whether the deaths were correctly attributed to asthma.

All death certificates issued in Auckland during the first six months of 1981 for people under 55 years of age and in which death was attributed to bronchitis, chronic obstructive respiratory disease, emphysema, respiratory failure, bronchopneumonia, congestive heart failure, and other related disorders that may have been confused with asthma were examined. In view of the small numbers of deaths in this age group in Auckland a sample of 1981 death certificates for the 55-69-year age group were also examined. Hospital records, coroners' reports, and, when necessary, reports from general practitioners were independently assessed by two respiratory physicians to check for inaccuracies in the reporting of deaths from asthma.

For a death to be attributed to asthma the reviewing physicians used the following criteria: $(a)$ presence of recent objective evidence of $20 \%$ reversibility of airflow obstruction or (b) a subjective impression of recent useful reversibility of airflow obstruction when objective data were not available, and (c) no history, physical findings, investigation, or postmortem evidence suggesting that asthma or its treatment was not the primary cause of death.

\section{Population changes}

Crude asthma mortality rates for the 5-34-year age group in New Zealand during $1959-78^{7}$ were standardised for age to the $1969 \mathrm{New}$ Zealand population using the direct method, and changes in the racial composition of the population examined ${ }^{15}$ to determine their influence on mortality rates.

\section{Results}

\section{INTERNATIONAL TRENDS IN ASTHMA MORTALITY}

Figure 1 shows the trends in asthma mortality in 5-34-year-olds in the six populations during 1959-79.

In England and Wales death rates from asthma increased threefold between 1959 and 1966, from $0 \cdot 7$ to $2 \cdot 2$ per 100000 persons (123 deaths in 1959 to 431 deaths in 1966). The rate subsequently declined as rapidly as it had increased and had almost reached the 1959 level by 1970 . Since then it has been relatively stable.

The trend in Australia was similar to that in England and Wales, rising from an average of 1.1 deaths per 100000 in 1959-63 (about 55 deaths a year) to a peak of 1.9 in 1966 (105 deaths) and then declining. The Australian rate, however, was consistently higher than in England and Wales both before and after the epidemic.

In New Zealand the mortality rate started to rise in 1965, several years later than in England and Wales and Australia, and rose abruptly to about three times the pre-epidemic level (table). There were some fluctuations in death rates over the next eight years and, although there was a gradual downward trend, mortality remained at least one and a half times the pre-epidemic level. In 1976 mortality again began to rise steeply and subsequently remained high. The current rate in New Zealand is four times both the pre-epidemic rate and the current rate in England and Wales and Australia. For the years 1977-9 this represented, on average, 44 extra deaths from asthma a year in the 5-34-year age group in New Zealand when compared with the Australian rates.

In the United States and Canada asthma mortality in this age group remained remarkably stable and low. During the study period (195979) the rate was maintained at between 0.2 and 0.4 deaths per

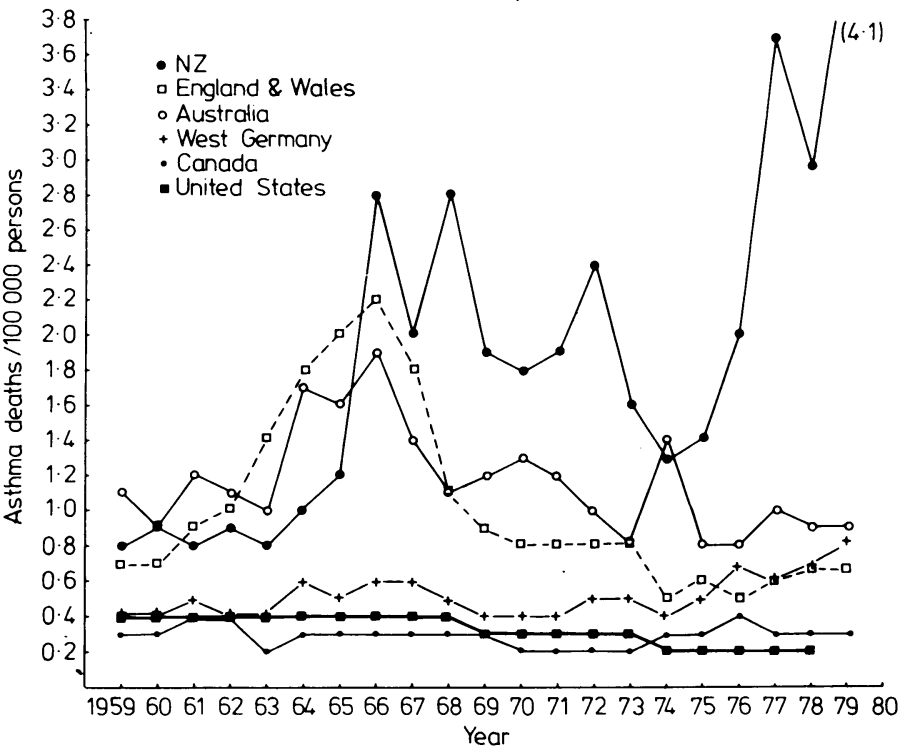

FIG 1-Asthma mortality in 5-34-year-olds in six countries during 1959-79.

100000 . Though marginally higher, mortality in West Germany followed a similar course to that in the United States and Canada until the early 1970s. Subsequently, however, there appeared to have been an upward trend in deaths from asthma, rising from 0.4 per 100000 persons in $1970-1$ to $0 \cdot 8$ in 1979 .

\section{INTERPRETATION OF TRENDS}

\section{Changes in classification}

After 1959 there had been three revisions of the ICD. Deaths from asthma reported for 1959-67 were coded 241 in the seventh revision; in the eighth revision (1968-78) and ninth revision (1979-80) they were coded 493. The classification of asthma was similar in the seventh and eighth revisions except that cases with coexistent emphysema were excluded in the eighth revision. It is unlikely that the data presented here would be affected to any measurable degree by this change because death from emphysema (with or without reference to asthma) occurs rarely in the 5-34-year age group. During the mid-1970s in this age group the average yearly number of deaths from emphysema was only 8 in England and Wales, 4 in Australia, and 0 in New Zealand.

The change from the eighth revision to the ninth revision was of more importance. In the eighth revision bronchitis, unspecified as acute or chronic (490) with mention of asthma, was coded as bronchitis, whereas under the ninth revision it was coded as asthma unspecified (493.9). Lambert reported on a sample of deaths from asthma in England in 1978 which were coded under both the eighth and ninth revisions of the ICD. ${ }^{16}$ When this "bridge coding" was confined to those aged under 45 the increase attributed to the selection rules of the ninth revision was $9 \%$. It was likely to be even less in the 5-34year age group because their death rate for bronchitis is consistently much lower than among 35-44-year-olds.

Numbers of deaths and death rates from asthma per 100000 persons aged 5-34 years ${ }^{7}$ : New Zealand, 1959-79

\begin{tabular}{|c|c|c|c|c|c|c|c|c|c|c|c|c|c|c|c|c|c|c|c|c|c|}
\hline & 1959 & 60 & 61 & 62 & 63 & 64 & 65 & 66 & 67 & 68 & 69 & 70 & 71 & 72 & 73 & 74 & 75 & 76 & 77 & 78 & 79 \\
\hline $\begin{array}{l}\text { No } \\
\text { Rate }\end{array}$ & $\begin{array}{l}9 \\
0 \cdot 8\end{array}$ & $\begin{array}{c}10 \\
0.9\end{array}$ & $\begin{array}{l}9 \\
0 \cdot 8\end{array}$ & $\begin{array}{r}11 \\
0.9\end{array}$ & $\begin{array}{l}10 \\
0.8\end{array}$ & $\begin{array}{l}13 \\
1.0\end{array}$ & ${ }_{1}^{16}$ & $\begin{array}{c}38 \\
2 \cdot 9\end{array}$ & $\stackrel{27}{2 \cdot 0}$ & ${ }_{3.0}^{41}$ & $\stackrel{27}{1.9}$ & $\stackrel{26}{1.8}$ & $\begin{array}{r}28 \\
1.9\end{array}$ & $\begin{array}{l}36 \\
2 \cdot 4\end{array}$ & $\stackrel{24}{1.6}$ & 21 & $\begin{array}{c}23 \\
1.4\end{array}$ & $\begin{array}{c}33 \\
2 \cdot 0\end{array}$ & ${ }_{3 \cdot 7}^{61}$ & $\begin{array}{l}49 \\
3.0\end{array}$ & $\begin{array}{c}68 \\
4 \cdot 1\end{array}$ \\
\hline
\end{tabular}

Provisional figures for 1980: 56 deaths, rate $3 \cdot 4$ 
Figure 2 shows the yearly death rates for 1968-78 in each of the six populations for all respiratory diseases other than asthma in the 5-34year age group. The period reviewed was limited to the years covered by the eighth revision of the ICD (1968-78) to avoid problems associated with changes in classification. Death rates for all respiratory diseases (other than asthma) were broadly similar in each country and showed a gradual decline over the period reviewed. In particular, the increase in asthma mortality in New Zealand in the late 1970s was not associated with a reciprocal decline in mortality from all other respiratory diseases.

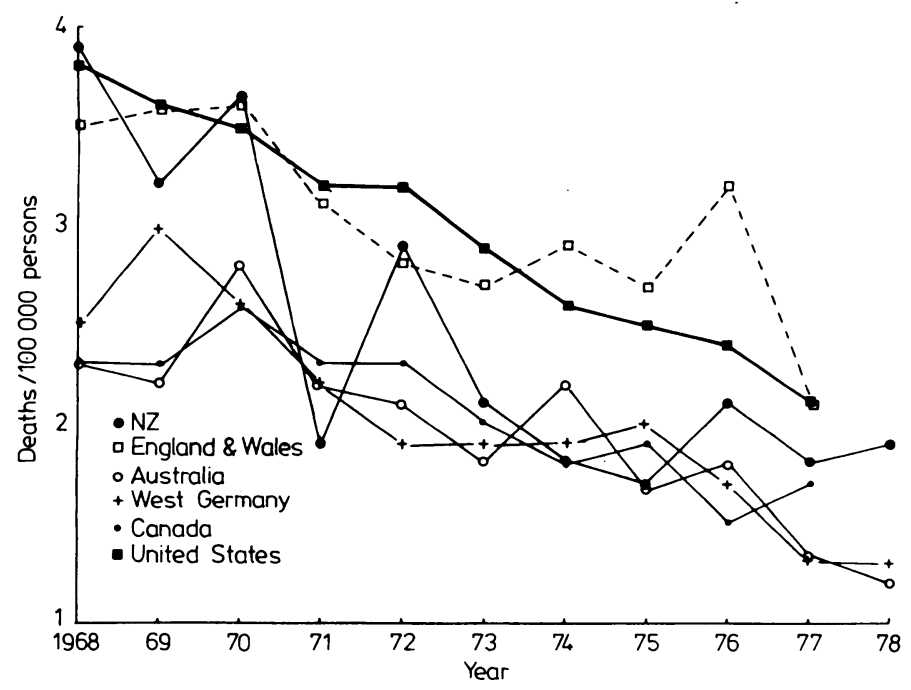

FIG 2-Mortality from all respiratory diseases other than asthma in 5-34year-olds in six countries during 1968-78.

\section{Death certificate validation}

The attempt to validate asthma death certification entailed searching for false-positive and false-negative reporting of deaths from asthma. Of the 18 people certified as dying from asthma in the 5-34-year age group in Auckland during 1981, all had asthma and all died from asthma according to the criteria used. Thus no evidence of falsepositive reporting was found. With regard to false-negative reporting, 76 death certificates in which death was attributed to disorders which could have been confused with asthma were identified. In 66 cases information on medical history and circumstances of death was available from hospital records or postmortem reports. Only one of these 66 people was considered to have died with asthma, but even in this case death could not confidently be attributed to asthma. Information on the other 10 subjects was obtained from telephone interviews with the general practitioners concerned, and on the basis of this information it was possible to exclude asthma as the cause of death in nine.

This investigation showed that at least in the 5-34-year age group during 1981 death certification of asthma in Auckland appeared to have been accurate. There was no reason to believe that it should be otherwise for the rest of New Zealand.

\section{Population changes}

Age standardisation of New Zealand asthma mortality for the period 1959-79 did not alter the pattern shown in fig 1. There was some evidence that asthma was more prevalent among Polynesians. ${ }^{7} 17$ There had been changes in the racial composition of the New Zealand population since $1959^{15}$ but the numbers were insufficient to account for the observed increase in mortality.

\section{Discussion}

This review showed a pronounced increase in deaths from asthma in New Zealand since the mid-1970s, a trend which was not apparent in the other five populations examined. Changes in classification of deaths from asthma in the various revisions of the ICD, inaccuracies in death certification, changes in diagnostic fashions, and changes in population structure and racial composition did not appear to account for this increase.

The 5-34-year age group was chosen to avoid major inaccuracies in the death certification of asthma. In this age group asthma is a reasonably clear-cut diagnosis, whereas under 5 years of age it may be confused with bronchitis or bronchiolitis, and in older age groups may be complicated by bronchitis, emphysema, and heart disease. Our investigation of asthma death certification in Auckland confirmed that it was accurate.

The similar death rates due to all respiratory diseases other than asthma, in all countries examined, suggested that differences in asthma mortality between these countries were real and did not reflect major differences in diagnostic fashions. Furthermore, a change in diagnostic fashion was unlikely to account for the recent increase in deaths attributed to asthma in New Zealand, as the death rate due to all other respiratory disease remained relatively stable in this period.

It therefore appears that the recent increase in mortality attributed to asthma in New Zealand represents a real increase in deaths from asthma. The cause of this new epidemic is, however, not apparent.

An increase in the prevalence of asthma cannot be excluded because there have been no population-based studies of asthma morbidity over time in New Zealand. It is of note that hospital admission rates for asthma have doubled in New Zealand since $1974^{18}$; this may, however, reflect a change in the criteria for admission rather than an increase in prevalence. Indeed a similar increase in hospital admissions for asthma has occurred in England in recent years ${ }^{19}$ with no associated increase in asthma mortality.

The other possible explanation is an increase in case fatality rate. Unfortunately we cannot test this directly, but the size and rapidity of the increase in mortality makes it, in our view, the most likely cause. Possible explanations include the following. (a) Asthmatics in New Zealand may have a more severe form of the disease. This seems unlikely as most of the populations reviewed have common ancestry. (b) Environmental factors peculiar to New Zealand. Environmental pollution, however, is not a major problem in New Zealand and records of airborne pollens and fungal spores are similar to those reported for the United States, Britain, and Scandinavia. (c) Changes in the management of asthma in New Zealand. This appears to be the most likely explanation. Some examples of changes in management previously described are an undue reliance on bronchodilator drugs to the exclusion of appropriate prophylaxis and delays in giving corticosteroids in the severe acute attack. ${ }^{36} 20$ Such factors also appear to be the most likely explanation for the 1960 s epidemic.

On the assumption that increased case fatality is responsible for the current epidemic in New Zealand, a major epidemiological study is under way which will hopefully identify causative factors. Whatever the explanation, the current epidemic of asthma mortality in New Zealand is cause for concern. Recognising this new epidemic in New Zealand should alert the profession to the possibility of similar trends occurring in other countries.

We thank Professor Sir Richard Doll for his comments and suggestions on an earlier draft of the paper; staff from the National Health Statistics Centre, Wellington, for help in extracting mortality data; and Mrs Jill Fenwick for her help in interviewing.

This study was funded in part by the Maurice and Phyllis Paykel Trust and the Auckland Asthma Society (Inc).

Requests for reprints should be sent to Dr Rodney T Jackson.

\section{References}

${ }^{1}$ Speizer FE, Doll R. A century of asthma deaths in young people. $\mathrm{Br} \mathrm{Med} \mathcal{F}$ 1968 ;iii :245-6. 
2 Gandevia B. Pressurized sympathomimetic aerosols and their lack of relationship to asthma mortality in Australia. Med $\mathcal{F}$ Aust 1973;i:273-7.

${ }^{3}$ Inman WHW, Adelstein AM. Rise and fall of asthma mortality in England and Wales in relation to use of pressurised aerosols. Lancet 1969 ;ii: 279-85.

4 Stolley PD, Schinnar R. Association between asthma mortality and isoproterenol aerosols: a review. Prev Med 1978;7:319-38.

${ }^{5}$ Speizer FE, Doll R, Heaf P. Observations on recent increases in mortality from asthma. $\mathrm{Br}$ Med $\mathcal{F} 1968 ; \mathrm{i}: 335-9$.

${ }^{6}$ Wilson JD, Sutherland DC, Thomas AC. Has the change to beta-agonists combined with oral theophylline increased cases of fatal asthma ? Lancet $1981 ; \mathrm{i}: 1235-7$.

${ }^{7}$ National Health Statistics Centre. New Zealand health statistics reportmortality and demographic data, 1959-79. Wellington: National Health Statistics Centre, Department of Health, annual.

* Office of Population Censuses and Surveys. Mortality statistics-cause. England and Wales. 1974-9. Series DH2. London: HMSO, annual.

${ }^{9}$ Commonwealth Bureau of Census and Statistics. Causes of death, Australia 1968-1979. Canberra: CBCS, annual.

10 National Centre for Health Statistics. Vital statistics of the United Statesmortality, 1968-1978. Hyattsville, Maryland: NCHS, annnal.

1 Herausgeber Statisches Bundesamt. Gesundheitswesen. Todesursachen. 1974-1979. Wiesbaden: Herausgeber Statisches Bundesamt, annual.
12 Statistics Canada. Vital statistics 1974-1979. Ottawa: Statistics Canada, annual.

13 World Health Organisation. World health statistics annual: vital statistics and causes of death. 1967-1980. Geneva: WHO, annual.

14 World Health Organisation. International classification of diseases. 7 th $\widehat{\Omega}$ revision, 1955 ; 8 th revision, $1965 ; 9$ th revision, 1975 . Geneva: WHO, 1957, 1967, 1977.

15 Department of Statistics. New Zealand Census of population and dwellings 1961-1981. Wellington: Department of Statistics, 1962, 1967, 1972, 1977, 1982.

16 Lambert PM. Lancet 1981 ;ii:200-1.

17 Mitchell EA, Elliot RB. Hospital admissions for asthma in children: a $\overrightarrow{\bar{T}}$ prospective study. NZ Med F $1981 ; 94: 331-4$.

18 Department of Health. Trends in health and health services 1979. New Zealand: Department of Health, 1980.

19 Anderson HR, Bailey P, West S. Trends in the hospital care of acute $\overline{\bar{c}}$ childhood asthma 1970-8: a regional study. $\mathrm{Br} M e d \mathcal{f} 1980 ; 281: 1191-3$. $\overrightarrow{\mathrm{D}}$

${ }^{20}$ Fraser PM, Speizer FE, Waters SDM, Doll R, Mann NM. The circumstances preceding death from asthma in young people in 1968 to 1969. $B r \mathcal{F}$ Dis Chest $1971 ; 65: 71-84$.

(Accepted 22 fuly 1982)

\title{
Nuclear magnetic resonance imaging of the brain in children
}

\author{
M I LEVENE, A WHITELAW, V DUBOWITZ, G M BYDDER, R E STEINER, C P RANDELL, \\ I R YOUNG
}

\begin{abstract}
A preliminary study of nuclear magnetic resonance imaging of the brains of four normal children (36 weeks' postmenstrual age to 5 years) showed long $T_{1}$ areas in the periventricular region of the neonate as well as evidence of progressive myelinisation with increasing age. Study of 18 patients of 40 weeks' postmenstrual age to 4 years showed an apparent deficit in myelinisation in an infant with probable rubella embryopathy and another with ventricular dilatation of unknown cause. Abnormal scans were obtained in an infant with congenital muscular dystrophy, and abnormalities were visualised at the lateral ventricular margins in a case of acute hydrocephalus after shunt blockage. Periventricular regions of increased $T_{2}$ were seen in a term infant aged 4 days after severe birth asphyxia and convulsions.

Nuclear magnetic resonance imaging appears to provide a unique demonstration of myelinisation in vivo and shows changes in pathological processes of importance in paediatric practice.
\end{abstract}

\section{Introduction}

Examination of the brain with nuclear magnetic resonance imaging in adults shows several features which may be particu-ō larly applicable to paediatric practice. A high level of contrast between grey and white matter is seen, ${ }^{1}$ suggesting that pro- $\Omega$ gressive myelinisation may be detected and hence delays in $\vec{F}$ this process may be recognised. Also the technique is sensitive 3 to cerebral oedema and ischaemic change in adults ${ }^{2}{ }^{3}$-con- $=$ ditions difficult to recognise in neonates with $x$-ray computedo tomography or ultrasound.

To examine the potential of nuclear magnetic resonance imaging of the brain in infancy we have conducted a preliminary. study of four normal children and 18 patients with various 3 neurological conditions and compared the results with ultrasound or $x$-ray computed tomography in most cases.

\section{Subjects and methods}

With the approval of the ethical committee of the Royal Postgraduate Medical School we studied four normal infants and 18 patients. In each case the parents gave informed consent. The normal subjects comprised an infant of 5 weeks born after 31 weeks of gestation and children aged 6 months, 20 months, and 5 years. The newborn infant? had shown hypotonia, which had disappeared by the time of theo nuclear magnetic resonance scan. The 18 patients ranged in age from

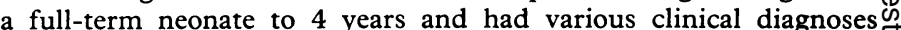
(table I). Six had intraventricular haemorrhage diagnosed by real-time 0 ultrasound ${ }^{4} ;$ three of these children subsequently developed ventricular dilatation, and one also had a porencephalic cyst. One patient with ventricular dilatation had a cephalhaematoma. Ultrasound examina- $\frac{\mathcal{P}}{\mathbb{D}}$ tion was performed in 14 patients and $x$-ray computed tomography $\varrho$ in two.

All nuclear magnetic resonance examinations conformed to guide- 8 lines provided by the National Radiological Protection Board for clinical imaging. Sedation with oral chloral hydrate $(75 \mathrm{mg} / \mathrm{kg})$ was given in 20 of the 23 nuclear magnetic resonance examinations $\frac{0}{5}$

\footnotetext{
Royal Postgraduate Medical School, Hammersmith Hospital, M I LEVENE, MD, lecturer in neonatal medicine A WHITELAW, $M D$, consultant paediatrician V DUBOWITZ, $M D$, professor of paediatrics and neonatal medicine G M BYDDER, MRCP, senior lecturer, department of diagnostic radiolog $R$ E STEINER, MD, FRCP, professor of diagnostic radiology

Hirst Research Laboratory, Wembley, Middlesex HA9 7PR

C P RANDELL, MSC, senior scientist

I R YOUNG, PHD, manager, Picker research laboratory
}

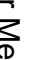

